\title{
Ultrasonographic evaluation of the renal dimensions in captive tigers
}

\author{
Somkiat HUAIJANTUG ${ }^{1)}$, Komsan MANATPREPREM ${ }^{2)}$, Sukhumarn MANATPREPREM ${ }^{2)}$ and Paranee YATMARK ${ }^{3) *}$ \\ 1)Department of Clinical Sciences and Public Health, The Faculty of Veterinary Science, Mahidol University, 999 Phuttamonthon 4 Road, \\ Salaya, Nakhon Pathom 73170, Thailand \\ 2) The Faculty of Veterinary Science, Mahidol University, 999 Phuttamonthon 4 Road, Salaya, Nakhon Pathom 73170, Thailand \\ 3) Department of Pre-Clinical and Apply Animal Science, The Faculty of Veterinary Science, Mahidol University, 999 Phuttamonthon \\ 4 Road, Salaya, NakhonPathom 73170, Thailand
}

(Received 6 November 2015/Accepted 5 August 2016/Published online in J-STAGE 3 September 2016)

ABSTRACT. Ultrasonographic measurements of kidney size are useful in the practical diagnosis of kidney diseases in animals. In tigers, there is a lack of information regarding the ultrasonography methods used to measure the kidney size of the tiger. Thirty-three healthy captive tigers (Panthera tigris) were placed in lateral recumbency for ultrasonography. The measurements obtained from the ultrasonography were computed, and the results showed that there was a statistically significant difference between genders in terms of body weight and renal length. The length of the right kidney was significantly different from that of the left kidney $(10.23 \pm 0.76 \mathrm{~cm}$ in males versus $9.94 \pm 0.80 \mathrm{~cm}$ in females; $P<0.05$ ). Interestingly, this study demonstrated that kidney length was statistically significantly associated with the body weight, and it also had a positive linear relationship with the body weight. Therefore, ultrasonographic renal dimensions could prove to be beneficial and modality for use in the evaluation of kidneys in unconscious tigers. However, kidney size evaluation must be performed using not only ultrasound but other clinical forms of technology and parameters.

KEY WORDS: aorta, captive tiger, renal dimentions, ultrasonography

doi: 10.1292/jvms.15-0635; J. Vet. Med. Sci. 78(12): 1759-1763, 2016

Ultrasonography has become an essential imaging tool for identifying abnormalities caused by several kidney diseases in human and veterinary medicine $[2-3,18]$. Ultrasound scan could be practical to assess the kidneys for important anatomical information concerning the size, shape and internal architecture [1]. Several kidney diseases may be associated with changes in renal dimensions or resistance index; this has been reported in dogs and cats due to acute inflammation, obstruction renal diseases and acute or chronic renal failure $[12,16]$. End-stage kidneys are usually small and irregular [14] and nephritis, renal abscess and renal failure leading to morphological changes are not usually diagnosed via radiographs or blood and urinary examination, whereas ultrasonography could be used for its detection.

In practice, ultrasonography must be performed on unconscious tigers, and the technique used to evaluate kidney size must be quick, simple and reliable. As for ratios comparing renal length with vertebrae in radiographs, relating ultrasonographic renal dimensions to obtain some indicators of body size could justifiably fulfill these conditions. The aortic diameter used as reliable landmark for ratio studies to quantify left atrial enlargement [8] was used to evaluate portal vein diameter in portosystemic shunt diagnosis [6]. It

*Correspondence to: Yatmark, P. Department of Pre-Clinical and Apply Animal Science, The Faculty of Veterinary Science, Mahidol University, 999 Phuttamonthon 4 Road, Salaya, Nakhon Pathom 73170, Thailand. e-mail: paranee.yat@mahidol.edu

(C)2016 The Japanese Society of Veterinary Science

This is an open-access article distributed under the terms of the Creative Commons Attribution Non-Commercial No Derivatives (by-nc-nd) License $<$ http://creativecommons.org/licenses/by-nc-nd/4.0/>. is also affirmed by other studies that relative changes in renal allograft size could be easily monitored by ultrasound [17].

Other studies have also reported the same could be done to obtain the renal dimensions and resistive index in other species including healthy dogs [5, 15], cats [20] and horses [13], and captive cheetahs with glomerulosclerosis and Iberian lynx with glomerulonephritis [4]. Although, there was a single case of pyelonephritis reported in a Siberian tiger [11], so far, no studies have investigated renal dimensions in healthy tigers. Therefore, the aim of this study was to evaluate the renal dimensions (height, length and width) and the aortic diameter in captive tigers using ultrasonography with the main purpose of generating information to establish reference intervals that could be used in practice and to analyze the basic factors that affect kidney size.

\section{MATERIALS AND METHODS}

Animal preparation and anesthesia: All 33 captive tigers (Panthera tigris) (21 females and 12 males) were used. Tigers are kept in The Bungchawak Zoo in Supanburi, Thailand and The Khao Prathap Chang Zoo in Ratchaburi, Thailand. Healthy adult captive tigers (Panthera tigris) were recruited into the present study, only if results from the physical examination were unremarkable. The complete blood count, serum and biochemical electrolyte values were normal for all tigers. The age and body weight were recorded for analyzing the relationship with renal dimensions. The protocol used in this study was approved by the Faculty of Veterinary Science-Animal Care and Use Committee, Mahidol University of Thailand. Each tiger was fasted for $12 \mathrm{hr}$ prior to general anesthesia. The tigers were anesthetized 
by intramuscular injection of atropine sulfate $(0.04 \mathrm{mg} / \mathrm{kg}$ body weight, T.P.Drug Lab Co., Ltd., Bangkok, Thailand), ketamine hydrochloride (4-5 mg/kg, body weight, Gedeon richter Ltd., Budapest, Hungary) and xylazine hydrochloride (1 mg/kg, body weigh, BIC Chemical Ltd., Nonthaburi, Thailand). During general anesthesia, diazepam $(0.5-1.0 \mathrm{mg} /$ kg, body weight, Siam Pharmaceutical Co., Ltd., Bangkok, Thailand) was also intravenously injected as an additional anesthetic drug. The duration of the anesthesia was no longer than $30 \mathrm{~min}$. After the procedures were performed, yohimbine hydrochloride $(0.125 \mathrm{mg} / \mathrm{kg}$, body weight, Bayer Thai Co., Ltd., Bangkok, Thailand) was intravenously injected for the reversal of xylazine immobilization [9, 21].

Ultrasonography: The captive tigers were placed in lateral recumbence for survey of ultrasonography. Transducerskin contact area was applied using a standard coupling gel. Real time B mode ultrasonographic images were obtained using a 3-5 MHz curvilinear electronic transducer attached to a Samsung Medison machine (Sonoace-R3, Samsung Medison, Seoul, Korea). Each kidney was evaluated with the lateral abdomen in the dorsal plane using a lateral transverse plane approach, and the maximal length of each kidney was measured by experienced sonographers. To obtain the maximal linear measurement, the renal length was observed after smooth rotation of the probe, while keeping the renal pelvis in the center and including the renal pelvis in the field of view. The maximal luminal diameter of the aorta was measured on the transverse and dorsal planes. The measurements were made from frozen images acquired at the maximal luminal diameter. The aortic luminal diameter was also measured in both the transverse and longitudinal planes just caudal to the origin of the left renal artery. Measurement cursors were placed at the margins of the lumen (excluding the vessel walls).

Statistical methods: The results are reported as the means \pm standard deviation, the minimum value and the maximum value (min-max). The correlation coefficient for the group means was calculated and compared using computerized statistical software (SPSS 19.0 for Windows, Chicago, IL, U.S.A.). The data sets for age, body weight, maximal length of the right and left kidneys and the maximal luminal diameter of the aorta were tested for normality using the Kolmogorov-Smirnov test. An independent T-test was used to compare significance differences between genders. A paired T-test was conducted to compare possible differences between the right and left kidneys. Spearman's correlation coefficient was used to assess the correlation between the body weight and the length of the kidney. Comparisons were considered statistically significance when $P<0.05$.

\section{RESULTS}

The effects of gender on renal dimensions and luminal diameter of the aorta in tigers: The age and body weight of the male and female tigers are presented in Table 1. There was a statistically significant difference between genders with males having a higher body weight than females $(161.91 \pm$ 38.43 versus $110.99 \pm 18.72 \mathrm{~kg} ; P<0.05)$.
Table 1. The effects of gender on renal dimensions and luminal diameter of the aorta in tigers

\begin{tabular}{llccc}
\hline \multicolumn{1}{c}{ Variables } & Sex & Range & Mean \pm SD & $P$-value \\
\hline Age & Male & $1.08-5.33$ & $3.25 \pm 1.50$ & 0.274 \\
(years) & Female & $1.08-10.00$ & $4.13 \pm 2.82$ & \\
Body weight & Male & $111-222$ & $161.91 \pm 38.43$ & $0.002^{\text {b) }}$ \\
(kg) & Female & $80-169$ & $110.99 \pm 18.72$ & \\
Rt length & Male & $9.60-11.95$ & $10.63 \pm 0.76$ & $0.017^{\text {a) }}$ \\
(cm) & Female & $9.00-11.55$ & $10.01 \pm 0.64$ & \\
Rt width & Male & $5.10-7.40$ & $6.22 \pm 0.76$ & 0.292 \\
(cm) & Female & $4.90-8.50$ & $5.91 \pm 0.82$ & \\
Rt height & Male & $4.90-7.65$ & $6.20 \pm 0.81$ & 0.325 \\
(cm) & Female & $4.90-7.50$ & $5.94 \pm 0.62$ & \\
Lt length & Male & $8.00-12.00$ & $10.32 \pm 0.86$ & $0.039^{\text {a) }}$ \\
(cm) & Female & $8.50-10.80$ & $9.72 \pm 0.70$ & \\
Lt width & Male & $5.20-7.00$ & $6.21 \pm 0.61$ & 0.183 \\
(cm) & Female & $4.80-7.90$ & $5.87 \pm 0.70$ & \\
Lt height & Male & $5.00-7.65$ & $6.51 \pm 0.77$ & 0.078 \\
(cm) & Female & $4.90-7.10$ & $6.05 \pm 0.61$ & \\
Ao transverse & Male & $1.00-1.40$ & $1.18 \pm 0.11$ & 0.507 \\
(cm) & Female & $0.90-2.00$ & $1.13 \pm 0.23$ & \\
Ao dorsal & Male & $0.98-2.00$ & $1.21 \pm 0.26$ & 0.326 \\
(cm) & Female & $0.90-1.80$ & $1.13 \pm 0.20$ & \\
\hline
\end{tabular}

$\mathrm{Rt}=$ Right kidney, Lt=Left kidney, Ao transverse=luminal diameter of the aorta measured on transversal planes, Ao dorsal=luminal diameter of the aorta measured on longitudinal planes. a) Statistically significant at the 0.05 level ( $P$-value). b) Statistically significant at the 0.01 level ( $P$-value).

Ultrasound imaging of the kidney length as shown in Fig. 1A, the luminal diameter of the aorta was measured on transverse (Fig. 1B) and longitudinal (Fig. 1C) planes. Males had a greater renal length than females (right renal length $10.63 \pm 0.76 \mathrm{~cm}$ versus $10.01 \pm 0.64 \mathrm{~cm} ; P<0.05$ and left renal length $10.32 \pm 0.86 \mathrm{~cm}$ versus $9.72 \pm 0.70 \mathrm{~cm} ; P<0.05$, respectively). On the other hand, there was no statistically significant difference in width, height and diameter of the aorta found between the genders.

Comparisons of renal dimensions between right and left kidneys in tigers: Renal measurements of every tigers were performed on both sides (see Table 2). The mean length of the right kidney was significantly larger than that of left kidney $(10.23 \pm 0.76 \mathrm{~cm}$ versus $9.94 \pm 0.80 \mathrm{~cm} ; P<0.05)$, but the mean width and height were not different between the right and left kidneys. In addition, as the aortic diameter was constant within each tiger, there was no statistically significant difference between length/aortic transverse and length/aortic dorsal ratios and between those of the right and left kidneys.

Relationship of body weight to renal dimensions in tigers: The length of the left and right kidneys showed the significant correlation with body weight in male tigers ( $\mathrm{r}=0.641, P<0.05$ and $\mathrm{r}=0.677, P<0.01$, respectively), except for the length of the left and right kidneys in female ( $\mathrm{r}=0.411, P<0.05$ and $\mathrm{r}=0.312, P=0.08$, respectively), (Fig. 2). Spearman correlation indicates the direction of association between the length of kidney and the body weight of every tigers (left kidney; $\mathrm{r}=0.58, P<0.01$ and right kidney; $\mathrm{r}=0.544, P<0.01$, respec- 

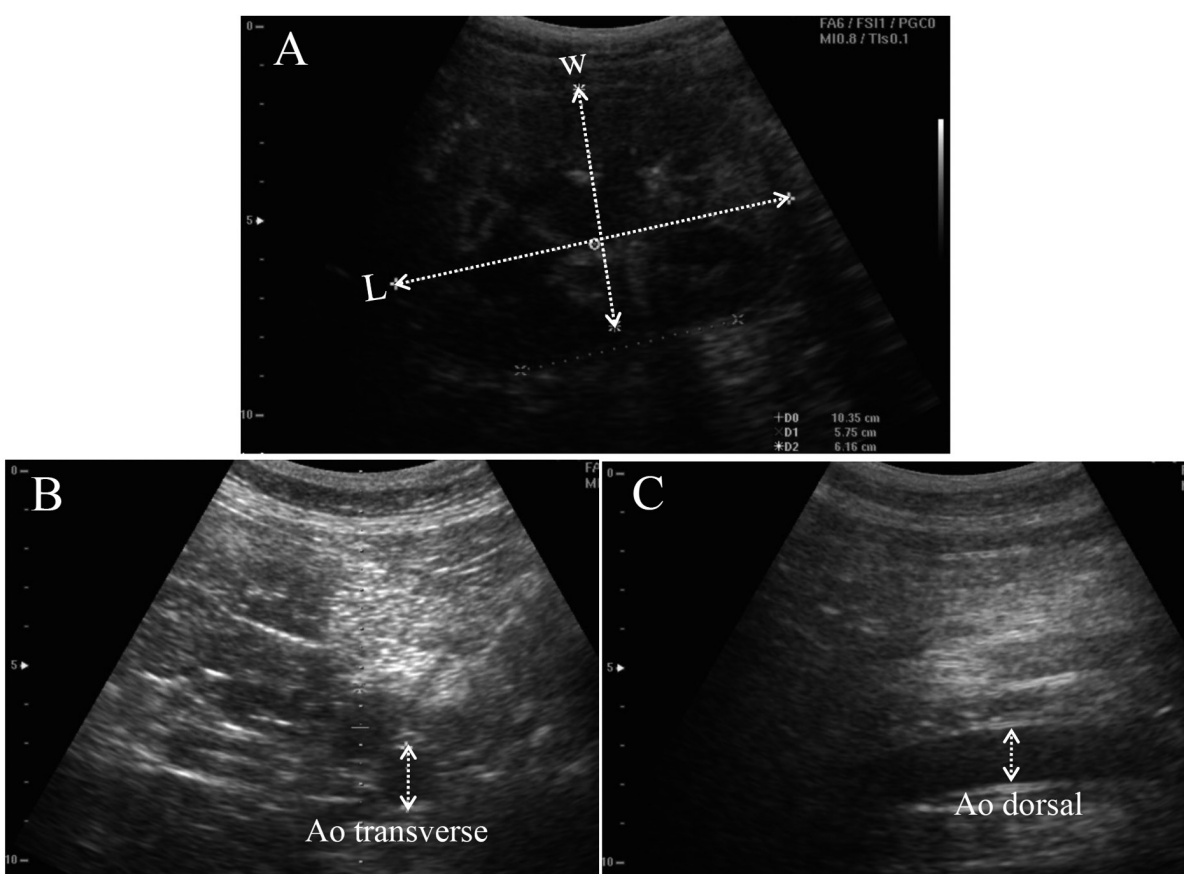

Fig. 1. Ultrasound images of the kidney on the dorsal plane (A) and the aorta on transverse (B) and longitudinal $(\mathrm{C})$ planes in tigers, $\mathrm{L}$, length of kidney; W, width of kidney; Ao, luminal diameter of the aorta.

Table 2. Comparisons of renal dimensions between right and left kidneys in tigers

\begin{tabular}{llllll}
\hline \multirow{2}{*}{ Renal dimension } & \multicolumn{2}{c}{ Right kidney } & & \multicolumn{2}{c}{ Left kidney } \\
\cline { 2 - 3 } \cline { 5 - 6 } & Min-Max & Mean $\pm \mathrm{SD}$ & & Min-Max & Mean \pm SD \\
\hline Length $(\mathrm{cm})$ & $9.00-11.95$ & $10.23 \pm 0.74^{\mathrm{a})}$ & & $8.00-12.00$ & $9.94 \pm 0.80$ \\
Width $(\mathrm{cm})$ & $4.90-8.50$ & $6.03 \pm 0.80$ & & $4.80-7.90$ & $6.01 \pm 0.68$ \\
Height $(\mathrm{cm})$ & $4.90-7.65$ & $6.05 \pm 0.70$ & & $4.90-7.65$ & $6.24 \pm 0.70$ \\
Length/Ao transverse & $5.78-10.89$ & $9.06 \pm 1.09$ & & $5.10-10.91$ & $8.82 \pm 1.21$ \\
Length/Ao dorsal & $5.88-10.65$ & $9.01 \pm 1.17$ & & $5.68-10.70$ & $8.76 \pm 1.22$ \\
\hline
\end{tabular}

Ao transverse=luminal diameter of the aorta measured on transversal planes, Ao dorsal=luminal diameter of the aorta measured on longitudinal planes. a) Statistically significant at the 0.01 level ( $P$-value).

tively), (Fig. 3), but not with the aorta diameter. However, the age did not relate with body weight or renal dimensions in this study.

\section{DISCUSSION}

The results revealed that the kidney size of the adult captive tigers was related to body weight and corresponded to the findings in domestic cats [20]. The kidney length and body weight were different between male and female tigers. The larger kidneys in males than females may be due to increased body weight, but the size of the kidney may also correlate with other factors associated with androgens. According to some authors, kidneys of adult male mice were larger than those of females, because of both the cellular hyperplasia and hypertrophy due to the influence of androgens
[10]. In addition, the length of the right kidney was greater than that of the left kidney, but opposing to those reported in dogs (the cranial margin of the right kidney was not clearly outlined for measurement in all dogs) [15]. Measuring the renal dimensions was difficult in tigers, because most of the tigers in our study had larger body size and high body condition scores (3.5-4). This can be overcome using the dorsal plane measurement and a low frequency transducer.

The present study used a ratio comparing renal length with aorta diameter, because the weight ranges of the tigers were significantly different, thus creating a relationship between the ultrasonographic renal measurements and the large body weight discrepancies in this species. However, no relation between the kidney length and the aorta diameter of the tigers in this study was different from previous studies conducted using other species [19]. Furthermore, kidneys 
Male
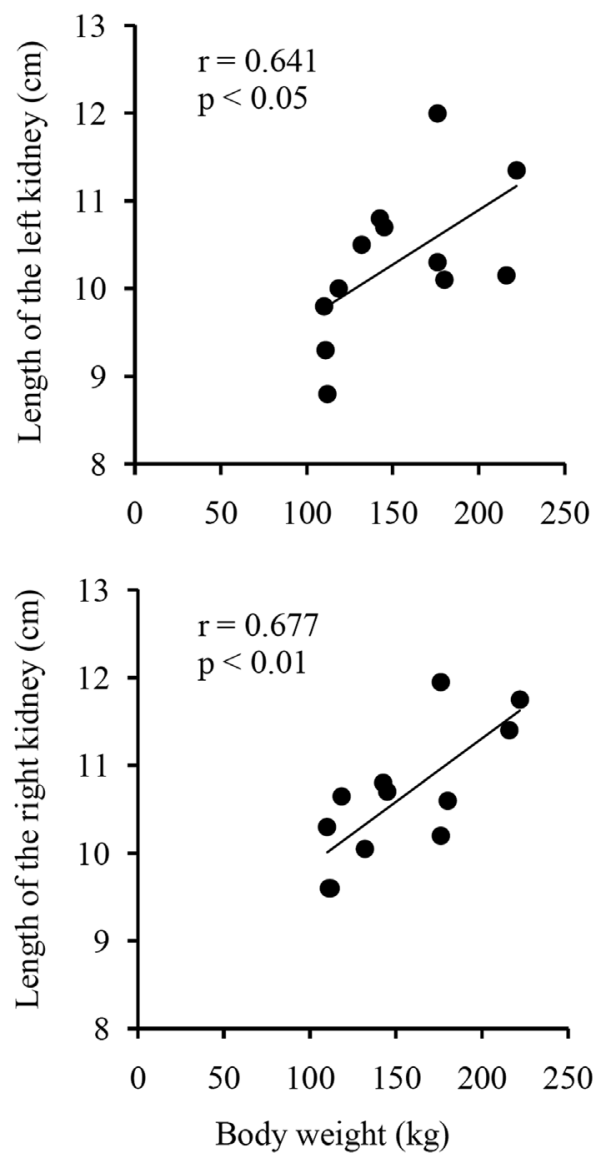

Female
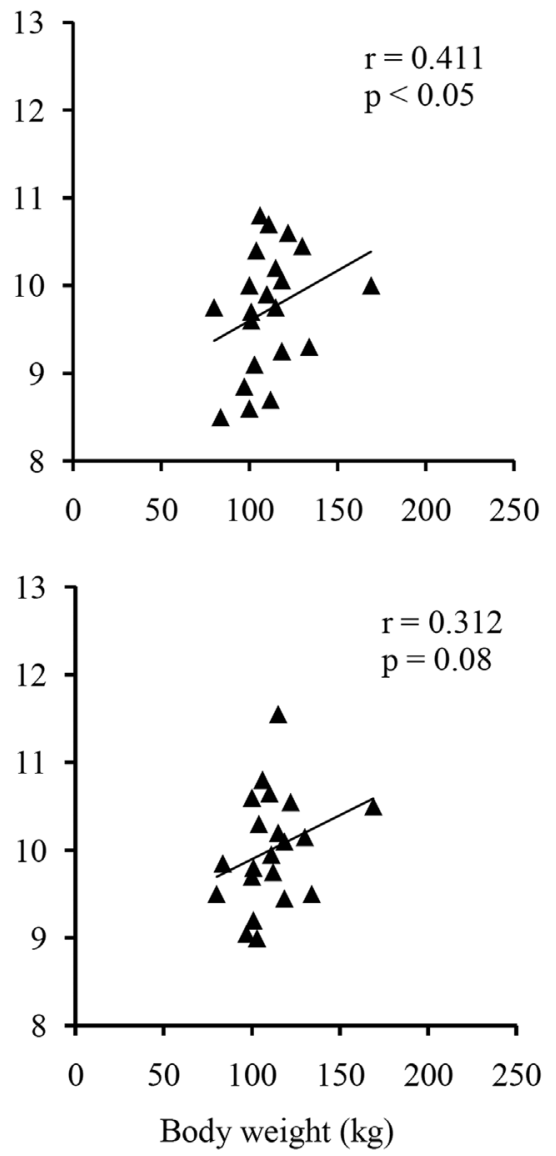

Fig. 2. Correlation between body weight and the length of the left and right kidneys in male and female tigers.
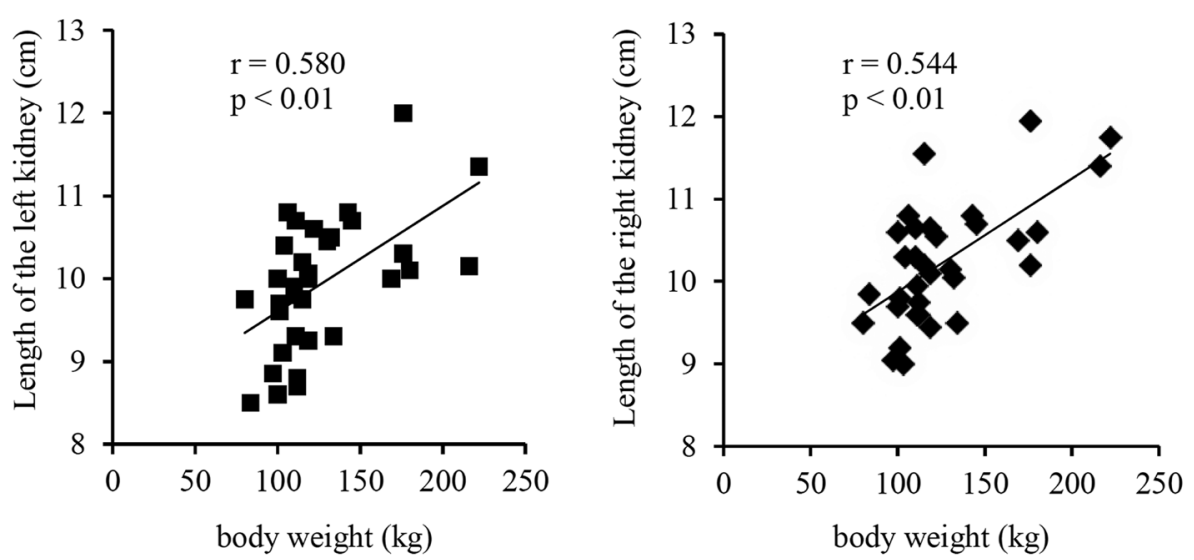

Fig. 3. Correlation between body weight and the length of the left and right kidneys in total tigers used in this study. The regression equation of the length of the left and right kidneys and body weight are $\mathrm{y}=24.59 \mathrm{x}-118$ and $\mathrm{y}=30.44 \mathrm{x}-184$, respectively. 
could be abnormal without a significant alteration in size [7]. Therefore, a ratio comparing renal length with aorta diameter should only be used to indicate abnormal renal size and only as one parameter in the ultrasonographic evaluation of kidney disease. Other clinical forms of technology and parameters should be considered to assess renal function and abnormal structures.

Regarding limitations, it is noted that although the measurement method of the present study could be reproducible by experienced sonographers, the level of experience required to reliably obtain these values was not examined. However, authors believe that these renal dimensions could be used as reference in tigers. Additionally, the population used in this study was dominated by a high female-to-male ratio, and therefore, the results obtained from this population may be lower than expected. It is therefore suggested that an equal number of adult male and female tigers be considered for further investigation.

In conclusion, ultrasonographic renal dimensions could prove to be beneficial and modality for use in the evaluation of kidneys in unconscious tigers. Kidney size evaluation must be performed using not only ultrasound but other clinical forms of technology and parameters. This study found that kidney length of tigers was associated with body weight, but not aorta diameter, and could be a reference interval used in ultrasonography in this feline species.

ACKNOWLEDGMENTS. This study was supported, in part, by a grant from the Faculty of Veterinary Science, Mahidol University of Thailand. The authors thank The Bungchawak Zoo in Supanburi, Thailand and The KhaoPrathap Chang Zoo in Ratchaburi, Thailand for supporting tigers to study.

\section{REFERENCES}

1. Armbrust, L. J., Biller, D. S., Hoskinson, J. J., Meier, H. T. and Lora-Michiels, M. 2001. The basics of renal ultrasonography. Vet. Med. 96: 114-133.

2. Babcock, D. S., Slovis, T. L., Han, B. K., McEnery, P. and McWilliams, D. R. 1985. Renal transplants in children: long-term follow-up using sonography. Radiology 156: 165-167. [Medline] [CrossRef]

3. Barr, F. J., Holt, P. E. and Gibbs, C. 1990. Ultrasonographic measurements of normal renal parameters. J. Small Anim. Pract. 31: 180-184. [CrossRef]

4. Bolton, L. A. and Munson, L. 1999. Glomerulosclerosis in captive cheetahs (Acinonyx jubatus). Vet. Pathol. 36: 14-22. [Medline] [CrossRef]

5. Chang, Y. J., Chan, I. P., Cheng, F. P., Wang, W. S., Liu, P. C. and Lin, S. L. 2010. Relationship between age, plasma renin activity, and renal resistive index in dogs. Vet. Radiol. Ultrasound 51: 335-337. [Medline] [CrossRef]

6. d'Anjou, M. A., Penninck, D., Cornejo, L. and Pibarot, P. 2004. Ultrasonographic diagnosis of portosystemic shunting in dogs and cats. Vet. Radiol. Ultrasound 45: 424-437. [Medline] [CrossRef]
7. Gary, R. J. 1995. Diagnostic imaging of the urinary tract. pp. 230-246. In: Canine and Feline Nephrology and Urology. (Osborne, C. A. and Finco, D. R. eds.), 1st ed. Lippincott Williams \& Wilkins, Philadelphia.

8. Hansson, K., Häggström, J., Kvart, C. and Lord, P. 2002. Left atrial to aortic root indices using two-dimensional and M-mode echocardiography in cavalier King Charles spaniels with and without left atrial enlargement. Vet. Radiol. Ultrasound 43: 568-575. [Medline] [CrossRef]

9. Herbst, L. H., Packer, C. and Seal, U. S. 1985. Immobilization of free-ranging African lions (Panthera leo) with a combination of xylazine hydrochloride and ketamine hydrochloride. J. Wildl. Dis. 21: 401-404. [Medline] [CrossRef]

10. Jean-Faucher, C., Berger, M., Gallon, C., de Turckheim, M., Veyssière, G. and Jean, C. 1987. Sex-related differences in renal size in mice: ontogeny and influence of neonatal androgens. $J$. Endocrinol. 115: 241-246. [Medline] [CrossRef]

11. Jee, H., Pakhrin, B., Bae, I. H., Shin, N. S., Lee, S. I., Yoo, H. S. and Kim, D. Y. 2007. Pyelonephritis associated with Staphylococcus intermedius in a Siberian tiger (Panthera tigris altaica). $J$. Vet. Med. Sci. 69: 851-852. [Medline] [CrossRef]

12. Kealy, J. K. 2000. The urinary system. pp. 112-117. In: Diagnostic Radiology and Ultrasonography of the Dog and the Cat. (Kealy, J. K. and McAllister, H. eds.), Mosby, St. Louis.

13. Macrì, F., Pugliese, M., Pietro, S. D., Coco, M. A., Liotta, L., Niutta, P. P., Nardi, S., Quartuccio, M., Lanteri, G. and Piccionello, A. P. 2015. Doppler Ultrasonographic Estimation of Renal Resistive Index in Horse: Comparison between left and right kidneys. J. Equine Vet. Sci. 35: 111-115. [CrossRef]

14. Mannion, P. 2006. Urinary tract. pp.109-127. In: Diagnostic Ultrasound in Small Animal Practice. 1st ed. Blackwell Science, Oxford.

15. Mareschal, A., d'Anjou, M. A., Moreau, M., Alexander, K. and Beauregard, G. 2007. Ultrasonographic measurement of kidneyto-aorta ratio as a method of estimating renal size in dogs. Vet. Radiol. Ultrasound 48: 434-438. [Medline] [CrossRef]

16. Nyland, T. G., Fisher, P. E., Doverspike, M., Hornof, W. J. and Olander, H. J. 1993. Diagnosis of urinary tract obstruction in dogsusing duplex Doppler ultrasonography. Vet. Radiol. Ultrasound 34: 348-352. [CrossRef]

17. Nyland, T. G., Fisher, P. E., Gregory, C. R. and Wisner, E. R. 1997. Ultrasonographic evaluation of renal size in dogs with acute allograft rejection. Vet. Radiol. Ultrasound 38: 55-61. [Medline] [CrossRef]

18. Nyland, T. G., Kantrowitz, B. M., Fisher, P., Olander, H. J. and Hornhof, W. J. 1989. Ultrasonic determination of kidney volume in the dog. Vet. Radiol. Ultrasound 30: 174-180. [CrossRef]

19. Nyland, T. G., Mattoon, J. S. and Herrgesell, E. J. 2002. Liver. pp.93-127. In: Small Animal Diagnostic Ultrasound. 2nd ed. W.B. Saunders Co., Philadelphia.

20. Park, I. C., Lee, H. S., Kim, J. T., Nam, S. J., Choi, R., Oh, K. S., Son, C. H. and Hyun, C. 2008. Ultrasonographic evaluation of renal dimension and resistive index in clinically healthy Korean domestic short-hair cats. J. Vet. Sci. 9: 415-419. [Medline] [CrossRef]

21. Seal, U. S., Armstrong, D. L. and Simmons, L. G. 1987. Yohimbine hydrochloride reversal of ketamine hydrochloride and xylazine hydrochloride immobilization of Bengal tigers and effects on hematology and serum chemistries. J. Wildl. Dis. 23: 296-300. [Medline] [CrossRef] 